\title{
COMUNICAÇÃO
}

\section{USO DE BIOESTIMULANTE NA VIDEIRA 'NIAGARA ROSADA'}

\author{
Plant growth regulators sprayings in 'Niagara Rosada' grape
}

\author{
Marco Antonio Tecchio ${ }^{1}$, Sarita Leonel ${ }^{2}$, Elizângela Clarete Camili \\ Gláucia Cristina Moreira ${ }^{3}$, Erasmo José Paioli-Pires ${ }^{4}$, João Domingos Rodrigues ${ }^{5}$
}

RESUMO

O experimento foi realizado no período de agosto a dezembro de 2004, em vinhedo de 'Niagara Rosada' localizado em PratâneaSP. O objetivo foi avaliar o efeito de bioestimulante nas características morfológicas e físico-químicas dos cachos de uva 'Niagara Rosada'. Os tratamentos consistiram na pulverização dos cachos com o bioestimulante nas doses de $0,5,10,15$ e $20 \mathrm{mg} \mathrm{L}^{-1}$, 25 dias após o pleno florescimento. $\mathrm{O}$ delineamento estatístico utilizado foi em blocos ao acaso com cinco repetições, e parcelas constituídas por 3 cachos. Analisou-se a massa fresca, comprimento e largura dos cachos e bagos, massa fresca do engaço, número de bagos por cacho, diâmetro do pedicelo, teor de sólidos solúveis totais, acidez titulável e o pH. Concluiu-se que o bioestimulante promoveu aumento linear no comprimento do cacho, aumento quadrático no diâmetro do pedicelo e um decréscimo linear no teor de sólidos solúveis totais.

Termos para indexação: Vitis, uva, reguladores vegetais, pós-colheita.

\begin{abstract}
The experiment was made during august until dezember/2004 period, in grape orchard of 'Niagara Rosada' located at Pratânea region, São Paulo, Brazil. The research had as purpose to study the effects of plant growth regulator (Stimulate) on morphological and physical-chemical characteristics of 'Niagara Rosada' grape. The clusters were sprayed with plant growth regulator solution at 0,5 , 10,15 e $20 \mathrm{mg} \mathrm{L}^{-1}, 25$ days after flowering. The experimental design was at randomized blocks with five replications and tree clusters per parcels. It was evaluated: the fresh weight of clusters and rachis, pedicel diameter, total soluble solids contents, titratable acid and $\mathrm{pH}$. The plant growth regulator spraying increased the clusters length and pedicel diameter and decreased the soluble solids contents.
\end{abstract}

Index Terms: Vitis, grapevine, plants regulators, postharvest.

(Recebido para publicação em 2 de junho de 2005 e aprovado em 31 de maio de 2006)

A utilização de reguladores vegetais em viticultura é uma prática que tem por objetivos, entre outros, a melhoria das características morfológicas dos cachos e bagos. Dentre os reguladores vegetais utilizados destacam-se as auxinas, giberelinas e citocininas. No entanto, o efeito de um determinado regulador vegetal varia em função da variedade, dose, modo e época de aplicação e das condições ambientais, havendo necessidade da realização de experimentos locais.

Atualmente, para a melhoria das características morfológicas dos cachos e bagos da videira, o regulador vegetal mais utilizado é o ácido giberélico (AG3), tendo como finalidade promover um aumento no tamanho e na fixação de bagos, descompactação de cachos e eliminação de sementes (PIRES \& BOTELHO, 2002). Segundo Métraux
(1988), as giberelinas podem promover o crescimento de órgãos vegetais pelo aumento do tamanho de células já existentes ou recentemente divididas. $\mathrm{O}$ crescimento das células pode ser acompanhado por um incremento no número de células e se dá mediante à elasticidade da parede e expansão celular. De acordo com Taiz \& Zeiger (1998), em relação à elasticidade, há evidências de que a enzima xiloglucano endotransglicosilase (XET) esteja envolvida na extensão da parede, facilitando a entrada de expansinas na parede celular, que por sua vez promove o rompimento das ligações de hidrogênio entre os polissacarídeos.

Botelho et al. (2003a), avaliando o efeito da aplicação de $100 \mathrm{mg} \mathrm{L}^{-1}$ de AG3 aos 14 dias após o florescimento, não obtiveram efeitos para o aumento na massa dos cachos e bagos, tamanho dos cachos e número de bagos. Cato (2003)

${ }^{1}$ Pesquisador Científico, Centro Avançado de Pesquisa Tecnológica do Agronegócio de Frutas - Instituto Agronômico de Campinas/IAC - 13214-280 Jundiaí, SP - tecchio@iac.sp.gov.br

${ }^{2}$ Professora Dr. Departamento do Produção Vegetal/Área Horticultura da Faculdade de Ciências Agronômicas/UNESP - Cx. P. 237 - $18603-970$ Botucatu, SP.

${ }^{3}$ Pós-graduando do Departamento de Produção Vegetal da Faculdade de Ciências Agronômicas/UNESP - Cx. P. 237 - $18603-970$ - Botucatu, SP. ${ }^{4}$ Pesquisador Científico, Instituto Agronômico de Campinas/IAC - Cx. P. 28 - 13001-970 - Campinas, SP - Bolsista do Cnpq.

${ }^{5}$ Professor Titular da Universidade Estadual Paulista/UNESP - Instituto de Biociências. Departamento de Botânica - Botucatu,SP. 
verificou que $35 \mathrm{mg} \mathrm{L}^{-1}$ de AG3 aplicados aos 15 dias após o pleno florescimento resultou em incremento na massa e tamanho médio dos cachos e bagos.

Razeto \& Espinoza (1990) e Retamales et al. (1995) relataram a importância de se obterem outros produtos para melhoria no tamanho dos bagos, uma vez que o ácido giberélico tem alguns efeitos indesejáveis como o aumento do vigor das plantas, com conseqüente redução na fertilidade das gemas, degrana dos cachos em pós-colheita e maior susceptibilidade dos frutos às podridões. Trabalhos mais recentes com outros reguladores vegetais contendo auxina e citocinina na sua composição, mostraram resultados promissores.

As auxinas aumentam a extensibilidade da parede celular, promovem a divisão celular, o crescimento das folhas, das raízes, e regulam o desenvolvimento dos frutos. Um grande número de auxinas sintéticas já foi produzido em laboratório, como as substâncias endólicas, os derivados do ácido benzóico, e os tiocarbamatos (TAIZ \& ZAEIGER, 1998). No entanto, em viticultura, o produto que vem sendo mais utilizado é o Quinmerac ou IUPAC (ácido 7-cloro-3-metilquinolina-8-carboxílico). Este regulador de crescimento apresenta um modo de ação semelhante ao da auxina, promovendo o alongamento e o aumento no volume celular, tendo como resultado frutos maiores e mais pesados (PIRES, 1998).

As citocininas são substâncias derivadas da purina adenina que promovem a divisão celular, a mobilização de nutrientes, a formação e a atividade dos meristemas apicais, o desenvolvimento floral, a germinação de sementes, a quebra de dormência de sementes e gemas, expansão celular, desenvolvimento de frutos, hidrólise de reservas de amido, retardo na senescência e dominância apical (TAIZ \& ZEIGER, 1998). O thidiazuron (TDZ) e o forclorfenuron (CPPU) são as citocininas mais empregadas na viticultura.

Alguns trabalhos mostram que a mistura de reguladores vegetais também promove uma melhoria na qualidade dos frutos de videira. Botelho et al. (2003b), em experimento realizado com 'Niagara Rosada' na região de Jundiaí, obtiveram maior massa, comprimento e largura de bagos nos tratamentos com TDZ $10 \mathrm{mg} \mathrm{L}^{-1}$ associado ao AG3 100 mg.L-1.

Com base no exposto, verificam-se bons resultados com a mistura de reguladores vegetais nas características dos cachos e bagos de videira. No entanto, poucos são os produtos hoje disponíveis no mercado que contenham a mistura de reguladores vegetais. Trabalhos com bioestimulante na área de fruticultura são escassos, não havendo relatos em viticultura.
Este trabalho teve por finalidade avaliar os efeitos da aplicação do bioestimulante Stimulate ${ }^{a ̂}$ nas características morfológicas e físico-químicas, dos cachos da videira 'Niagara Rosada', cultivada no município de Pratânea-SP.

O experimento foi realizado num vinhedo de Niagara Rosada', de 6 anos de idade, conduzida em espaldeira, enxertada sobre o porta-enxerto IAC 766 'Campinas', em propriedade localizada no município de Pratânea-SP.

Realizou-se a poda de produção no dia 12/08/04. Os tratamentos foram realizados no dia 22/10/04, aos 25 dias após o pleno florescimento, pela pulverização dos cachos com solução aquosa do bioestimulante Stimulate ${ }^{a}$ a $0,5,10,15$ e $20 \mathrm{mg} \mathrm{L}^{-1}$. O Stimulate ${ }^{\hat{a}}$, fabricado pela Stoller, é um bioestimulante que contém em sua fórmula $0,09 \mathrm{~g} \mathrm{~L}^{-1}$ de cinetina (citocinina), $0,05 \mathrm{~g} \mathrm{~L}^{-1}$ de ácido giberélico (giberelina) e $0,05 \mathrm{mg} \mathrm{L}^{-1}$ de ácido indol-butírico (auxina).

$\mathrm{O}$ delineamento experimental foi em blocos casualizados, com cinco repetições e parcelas constituídas por três cachos numa mesma planta. Com os frutos sazonados, realizou-se a colheita no dia 15/12/04. Após a colheita, os cachos foram transportados para o Laboratório de Frutas e Hortaliças da Faculdade de Ciências Agronômicas - UNESP/Botucatu, onde foram avaliadas as variáveis massa fresca dos cachos, bagos e engaço, comprimento e largura dos cachos e bagos; número de bagos por cacho e diâmetro do pedicelo.

Para se obter a massa fresca média dos cachos e bagos utilizou-se uma balança semi-analítica, com precisão de $0,1 \mathrm{~g}$, e, para a obtenção das dimensões dos bagos (amostra de 10 bagos por cacho) e do diâmetro do pedicelo (amostra de 3 bagos por cacho), utilizou-se um paquímetro digital. Os teores de sólidos solúveis totais da polpa, expressos em graus Brix, foram medidos com refratômetro tipo ABBE (marca Atago NI) a $25^{\circ} \mathrm{C}$. Para a acidez titulável, expressa em gramas de ácido tartárico por $100 \mathrm{~g}$ de polpa obtida por titulação com hidróxido de sódio $(\mathrm{NaOH})$ 0,1 N, utilizou-se uma amostra de $10 \mathrm{~g}$ do material fresco triturado e diluído em $100 \mathrm{~mL}$ de água destilada, conforme recomendação do Instituto Adolfo Lutz (1985). O pH foi obtido na polpa triturada dos bagos, utilizando-se um potenciômetro (Digital DMPH - 2), conforme técnicas recomendadas pelo Instituto Adolfo Lutz (1985).

Os dados foram analisados pelo programa SISVAR, realizando análise de variância e regressão polinomial. Para os dados significativos, ajustaram-se equações de regressão visando avaliar o comportamento das variáveis com o aumento das doses de Stimulate ${ }^{\hat{a}}$. 
Os resultados médios da massa fresca e largura do cacho, massa fresca do engaço e do número de bagos dos cachos de videira 'Niagara Rosada' encontram-se na Tabela 1. Tais variáveis não foram influenciadas pelo uso do Stimulate ${ }^{\hat{a}}$.

Verificou-se aumento linear no comprimento do cacho da 'Niagara Rosada' com a adição de Stimulate ${ }^{a}$ na solução (Figura 1). Embora o comprimento do cacho tenha sido afetado pelo uso de Stimulate ${ }^{\hat{a}}$, não foi possível um ajuste adequado dos dados, conforme pode ser observado pelo baixo coeficiente de determinação. O uso do Stimulte, proporcionou, em relação à testemunha, um acréscimo dessa variável de $8,3 \%$ com a dose de $20 \mathrm{mg} \mathrm{L}^{-1}$ de Stimulate ${ }^{\hat{a}}$.

Na Tabela 2, são expressos os valores médios da massa fresca, comprimento e largura dos bagos, acidez titulável e pH dos cachos de videira. Notou-se que, essas variáveis não foram influenciadas pelo uso de Stimulate ${ }^{\hat{a}}$, não havendo modelo de regressão significativo para expressão dessas medidas.
Quanto aos resultados referentes ao $\mathrm{pH}$ e a acidez titulável dos bagos observou-se uma média de, respectivamente, 3,15 e $0,91 \mathrm{~g}$ de ácido tartárico $100 \mathrm{~g}^{-1} \mathrm{de}$ polpa nos tratamentos, não havendo no entanto modelos de regressão para expressar essas variáveis, sendo os valores de $\mathrm{F}$ da análise de variância não significativa.

Em trabalho com videira 'Niagara Rosada', Vieira (2004) concluiu que duas aplicações de ácido giberélico, thidiazuron e quinmerac promoveram a divisão celular, enquanto a expansão celular foi observada com uma única aplicação de thidiazuron e quinmerac. A autora também não observou diferenças significativas para as variáveis acidez titulável e pH do mosto de uvas, relação comprimento largura dos bagos de uvas tratadas com ácido giberélico.

Doses crescentes de Stimulate ${ }^{\hat{a}}$ proporcionaram um aumento quadrático no diâmetro do pedicelo, sendo o ponto de máximo representado pela dose de $15 \mathrm{mg} \mathrm{L}^{-1}$ (Figura 2). O maior diâmetro do pedicelo tem grande importância na pós-colheita por diminuir a degrana, sendo bastante acentuada na variedade Niagara Rosada.

TABELA 1 - Resultados médios da massa fresca e largura do cacho, massa fresca do engaço e do número de bagos dos cachos de videira 'Niagara Rosada' submetidos a doses crescentes de Stimulate?. FCA/UNESP, Botucatu/SP, 2005.

\begin{tabular}{ccccc}
\hline Dose & \multicolumn{2}{c}{ Cachos } & & \\
\cline { 2 - 5 } Stimulate & Massa fresca (g) & Largura (mm) & Massa fresca engaço $(\mathbf{g})$ & $\mathbf{N}^{\mathbf{0}}$ de bagos \\
\hline Média & 255,6 & 82,9 & 5,3 & 56 \\
CV $(\%)$ & 9,4 & 6,7 & 12,7 & 7,31 \\
\hline
\end{tabular}

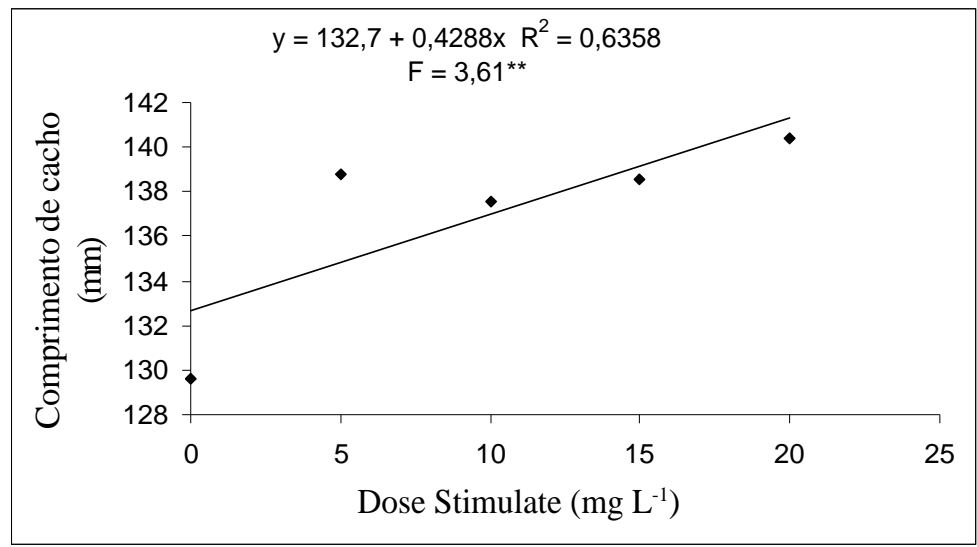

FIGURA 1 - Resultados médios do comprimento do cacho, em mm, da videira 'Niagara Rosada', submetida a doses crescentes de Stimulate', aos 25 dias após o florescimento. FCA/UNESP, Botucatu/SP, 2005.

Ciênc. agrotec., Lavras, v. 30, n. 6, p. 1236-1240, nov./dez., 2006 
TABELA 2 - Resultados médios da massa fresca, comprimento e largura dos bagos, acidez titulável e pH dos cachos de videira 'Niagara Rosada' submetidos à aplicação de doses crescentes de Stimulate? FCA/UNESP, Botucatu/SP, 2005.

\begin{tabular}{|c|c|c|c|c|c|}
\hline \multirow{2}{*}{$\begin{array}{c}\text { Dose } \\
\text { Stimulate }\end{array}$} & \multicolumn{3}{|c|}{ Bagos } & \multirow[b]{2}{*}{ Acidez titulável } & \multirow[b]{2}{*}{ pH } \\
\hline & MF (g) & Comp. & Largura & & \\
\hline & & $(\mathrm{mm})$ & & $\left(\mathrm{g}\right.$ ac.tartárico. $\left.100 \mathrm{~g}^{-1}\right)$ & \\
\hline Média & 4,47 & 21,0 & 18,5 & 0,91 & 3,1 \\
\hline CV $(\%)$ & 7,43 & 2,89 & 2,37 & 16,9 & 2,2 \\
\hline
\end{tabular}

$\mathrm{MF}=$ massa fresca de bago (média de 10 bagos).

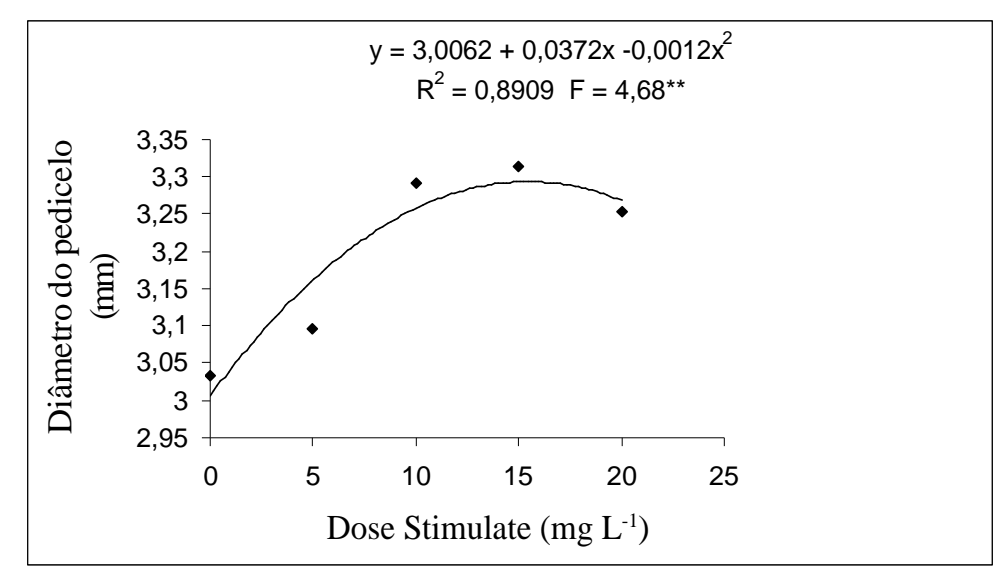

FIGURA 2 - Resultados médios do diâmetro do pedicelo, em mm, da videira 'Niagara Rosada', submetida a doses crescentes de Stimulate?, aos 25 dias após o florescimento. FCA/UNESP, Botucatu/SP, 2005.

Os valores de sólidos solúveis totais apresentaram um decréscimo linear com o aumento das doses de Stimulate ${ }^{\hat{a}}$, sendo que na dose mais elevada, houve uma diminuição de 7,18\%, em comparação com a testemunha, apresentando um coeficiente angular de $-0,0635$. A diminuição no teor de sólidos solúveis foi devida, provavelmente, a presença de citocinina na composição do bioestimulante, tendo em vista que este regulador vegetal promove um atraso no amadurecimento dos frutos.

De acordo com o relato de Métraux (1988), as giberelinas podem promover o crescimento de órgãos vegetais pelo aumento do tamanho de células já existentes ou recentemente divididas. Também Joublan et al. (1995) obtiveram resultados semelhantes aos do presente trabalho, quando observaram em uvas 'Moscatel Rosada' que a aplicação de ácido giberélico no cacho não aumentou a massa dos bagos, mas atrasou a maturação, bem como diminuiu a intensidade de cor nos bagos.
Pelos resultados obtidos verificaram-se resultados poucos expressivos na melhoria das características físicas dos cachos e bagos da videira 'Niagara Rosada' com a utilização do Stimulate ${ }^{\hat{a}}$, não justificando até o momento a utilização deste produto. No entanto, a tendência de aumento nas variáveis relacionadas às medidas dos cachos e bagos, justifica a continuidade de trabalhos com a utilização desse produto, havendo a necessidade de adequação da dose, modo de aplicação e/ou número de aplicações durante o ciclo da videira.

O emprego do Stimulate ${ }^{\hat{a}}$ promoveu aumento linear no comprimento do cacho, aumento quadrático no diâmetro do pedicelo e um decréscimo linear no teor de sólidos solúveis totais nos cachos da videira 'Niagara Rosada'. Não apresentou efeito sobre a massa fresca e largura dos cachos, no número, massa fresca, comprimento e largura dos bagos, massa fresca do engaço, na acidez titulável e no $\mathrm{pH}$. 


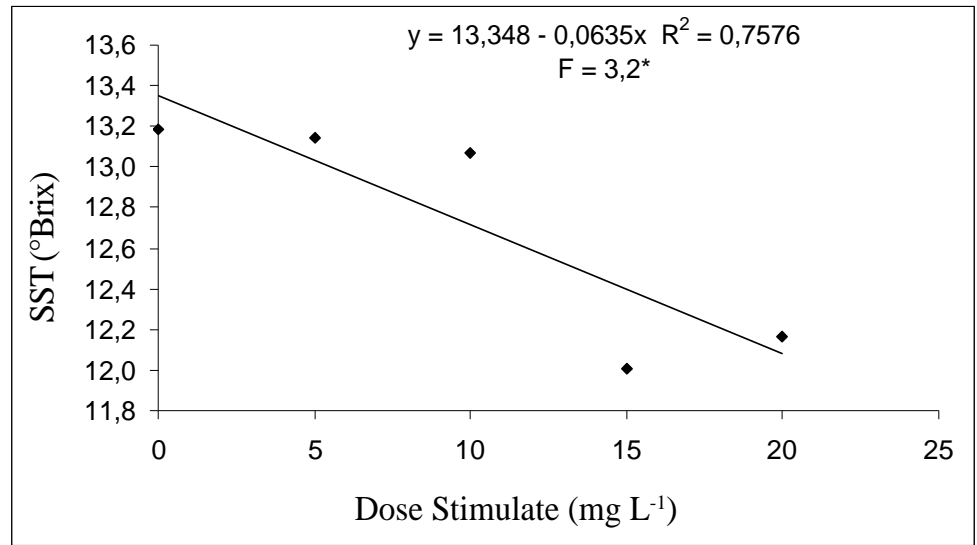

FIGURA 3 - Resultados médios do teor de sólidos solúveis totais, em ${ }^{\circ}$ Brix, da videira 'Niagara Rosada', submetida a doses crescentes de Stimulate?, aos 25 dias após o florescimento. FCA/UNESP, Botucatu/SP, 2005

\section{REFERÊNCIAS BIBLIOGRÁFICAS}

BOTELHO, R. V.; PIRES, E. J. P.; TERRA, M. M. Qualidade da uva de mesa 'Vênus' tratada com thidiazuron. Revista Ceres, Viçosa, v. 49, n. 286, p. 629-639, 2003a.

BOTELHO, R. V.; PIRES, E. J. P.; TERRA, M. M.; CARVALHO, C. R. L. Efeitos do thidiazuron e do ácido giberélico nas características dos cachos e bagos de uvas 'Niagara Rosada' na região de Jundiaí. Revista Brasileira de Fruticultura, Jaboticabal, v. 25, n. 1, p. 96-99, 2003 b.

CATO, S. C. Efeito do anelamento e de doses de ácido giberélico na frutificação das uvas 'Niagara Rosda'e 'Vênus'nas regiões noroeste e da alta paulista do Estado de São Paulo. 2002. 112 f. Dissertação (Mestrado em Agronomia) - Escola Superior de Agricultura Luiz de Queiroz, Piracicaba, 2003. Disponível em: <http:/ 'WwW.esalq.usp.bir >. Acesso em: 30 abr. 2004.

INSTITUTO ADOLFO LUTZ. Normas analíticas, métodos químicos e físicos para análise de alimentos. 3. ed. São Paulo, 1985. v. 1, 533 p.

JOUBLAN, M. J. P.; MERINO, H. R.; WILCKENS, E. R.; MEDINA, A. E. Efecto del CPPU y ácido giberélico en frutos de la vid cv Moscatel Rosada. AgroCiencia, [S.1.], v. 11, n. 2, p. 119-127, 1995.

MÉTRAUX, J. P. Gibberellins and plant cell elongation. In: DAVIES, P. J.Plant hormones and their role in plant growth and development. 2. ed. Ordrocht: Kluwer Academic, 1988. p. 296-317.

PIRES, E. J. P. Emprego de reguladores de crescimento em viticultura tropical. Informe Agropecuário, Belo Horizonte, v. 19, n. 194, p. 40-57, 1998.

PIRES, E. J. P.; BOTELHO, R. V. Emprego de reguladores de crescimento em viticultura. In: Viticultura e enologia: atualizando conceitos. Belo Horizonte: EPAMIGFECD, 2002. p. 59-81.

RAZETO, B.; ESPINOZA, J. Efecto del ácido giberélico y su forma de aplicación sobre las yemas y frutos de la vid cv Sultanina. Investigacion Agricola, Santiago, v. 10, p. 13-20, 1990.

RETAMALES, J.; BANGERTH, F.; COOPER, T.; CALLEJAS, R.; NITO, N.; LOONEY, N. E.; NEVINS, D. J.; HALEVY, A. H. Effects of CPPU and AG3 on fruit quality of Sultanina table grape. Acta Horticulturae, n. 394, p. 149$157,1995$.

TAIZ, L.; ZEIGER, E. Plant physiology. Califórnia: The Benjamin Cumings, 1998. 565 p.

VIEIRA, C. R. Y. I. Doses e épocas de aplicação do ácido giberélico, thidiazuron e quinmerac nas características dos cachos e bagos da videira 'Niagara Rosada'. 2004. 104 f. Tese (Doutorado em Horticultura) - Universidade Estadual Paulista, Campinas, 2004. 